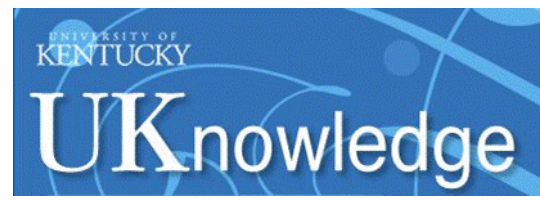

University of Kentucky

UKnowledge

\title{
A Tutorial on Learning Human Welder's Behavior: Sensing, Modeling, and Control
}

\author{
Y. K. Liu \\ University of Kentucky \\ W. J. Zhang \\ University of Kentucky \\ Yu Ming Zhang \\ University of Kentucky, yuming.zhang@uky.edu
}

Follow this and additional works at: https://uknowledge.uky.edu/ece_facpub

Part of the Electrical and Computer Engineering Commons

Right click to open a feedback form in a new tab to let us know how this document benefits you.

\section{Repository Citation}

Liu, Y. K.; Zhang, W. J.; and Zhang, Yu Ming, "A Tutorial on Learning Human Welder's Behavior: Sensing, Modeling, and Control" (2014). Electrical and Computer Engineering Faculty Publications. 1.

https://uknowledge.uky.edu/ece_facpub/1

This Article is brought to you for free and open access by the Electrical and Computer Engineering at UKnowledge. It has been accepted for inclusion in Electrical and Computer Engineering Faculty Publications by an authorized administrator of UKnowledge. For more information, please contact UKnowledge@lsv.uky.edu. 
A Tutorial on Learning Human Welder's Behavior: Sensing, Modeling, and Control

Digital Object Identifier (DOI)

http://dx.doi.org/10.1016/j.jmapro.2013.09.004

Notes/Citation Information

Published in Journal of Manufacturing Processes, v. 16, issue 1, p. 123-136.

Per the publisher Elsevier: "NOTICE: this is the author's version of a work that was accepted for publication in Journal of Manufacturing Processes. Changes resulting from the publishing process, such as peer review, editing, corrections, structural formatting, and other quality control mechanisms may not be reflected in this document. Changes may have been made to this work since it was submitted for publication. A definitive version was subsequently published in Journal of Manufacturing Processes, v. 16, issue 1, (January 2014). DOI: http://dx.doi.org/10.1016/j.jmapro.2013.09.004"

This article is available at UKnowledge: https://uknowledge.uky.edu/ece_facpub/1 


\title{
A Tutorial on Learning Human Welder's Behavior: Sensing, Modeling, and Control
}

\author{
Y.K. Liu, W.J. Zhang, Y.M. Zhang \\ Institute for Sustainable Manufacturing and Department of Electrical and Computer Engineering, University \\ of Kentucky, Lexington, KY, 40506 \\ *Corresponding Author, Phone: 859-323-3262, Fax:859-257-3092, Email:yuming.zhang@uky.edu
}

\section{Key Words}

Human Intelligence, Weld Pool, Sensing, Modeling, Control, GTAW

\begin{abstract}
Human welder's experiences and skills are critical for producing quality welds in manual GTAW process. Learning human welder's behavior can help develop next generation intelligent welding machines and train welders faster. In this tutorial paper, various aspects of mechanizing the welder's intelligence are surveyed, including sensing of the weld pool, modeling of the welder's adjustments and this model-based control approach. Specifically, different sensing methods of the weld pool are reviewed and a novel 3D vision-based sensing system developed at University of Kentucky is introduced. Characterization of the weld pool is performed and human intelligent model is constructed, including an extensive survey on modeling human dynamics and neuro-fuzzy techniques. Closed-loop control experiment results are presented to illustrate the robustness of the model-based intelligent controller despite welding speed disturbance. A foundation is thus established to explore the mechanism and transformation of human welder's intelligence into robotic welding system. Finally future research directions in this field are presented.
\end{abstract}

\section{Introduction}

In manual Gas Tungsten Arc Welding (GTAW) process skilled welders can appraise the state of weld joint penetration through their observation on the weld pool and intelligently adjust the welding parameters (e.g., current, welding speed, arc length and torch orientation) accordingly to control the weldingprocess. Because of their versatile sensing capability and experience-based behavior in response to the information they sense, they may be preferred over mechanized welding control systems in certain applications.

Although welders' experience and skills are crucial in producing quality welds, human welders have limitations. Critical welding operations require welders concentrate consistently in order to react rapidly and accurately. Inconsistent concentration, fatigue and stress do build up such that welders' capabilities degrade during daily operations. Moreover, experience and skills needed for critical operations typically require years to develop while manufacturing industry is experiencing insufficient number of skilled welders for a long time [1]. The mechanism of welder's experience-based behavior thus should be fully explored and utilized to develop intelligent robotic welding systems that combine human welder's intelligence and physical capabilities of the mechanized welding machines, which paves the foundation for next generation manufacturing processes. Modeling human welders' responses, i.e., how they respond to the information they sense, thus plays a fundamental role in facilitating such a development. In addition, the resultant welder response modelsmay also be utilized to understand why less skilled welders are not performing as well as skilled welders and help train welders faster in order to help resolve the skilled welder shortage issue the manufacturing industry is currently facing [2]. 
In the following subsections, fundamentals of GTAW process and analysis of human welder behavior are presented.

\subsection{GTAW Process}

GTAW is the primary process used by human welders for critical applications[3].In this process as shown in Fig. 1, an arc is established between the non-consumable tungsten electrode and base metal. The base metal is melted by the arc forming a liquid weld pool that joins the two pieces of base metal together after solidification. An optional filler metal (not shown in the figure) can be added if necessary but it is melted by the arc column, rather than directly by an arc spot as in gas metal arc welding (GMAW) where the anode can much more efficiently melt a continuously-fed wire than the arc column to increase the melting productivity. However, the detachment and impact of the associated droplets on the weld pool compromise the controllability of the process and limit its use in precision applications.

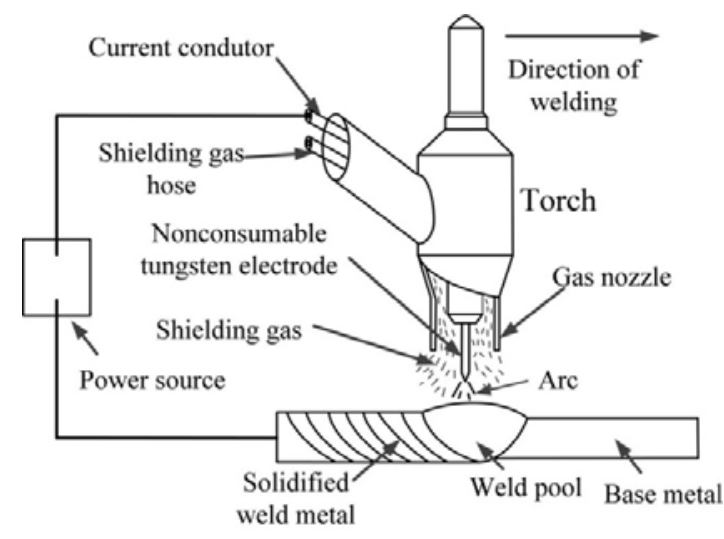

Fig. 1 Illustration of GTAW

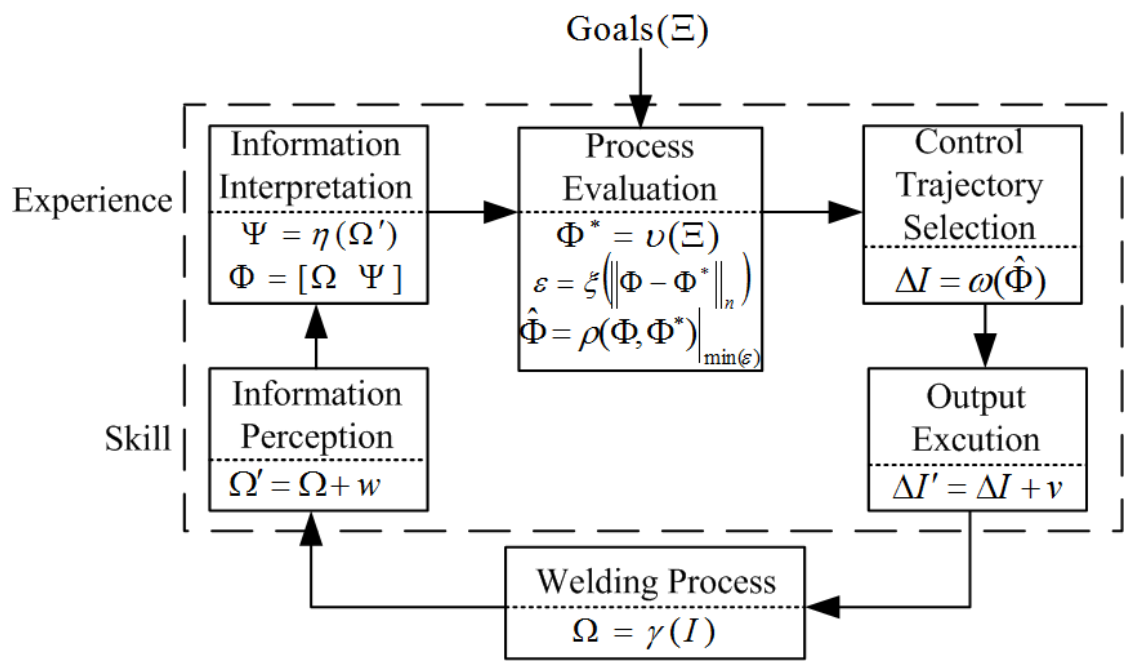

Fig. 2 Illustration of an interpretation of human welder's behavior [4].

Because GTAW is primarily used in applications where appropriate degree of full penetration is required, the process should be mechanized/automated. However, the assurance of the weld quality is generally not guaranteed in automated GTAW using conventional sensing method. In manual welding, welders observe the weld pool and assure the desired full penetration is produced. However, in mechanized welding, welders are not required or allowed to observe the welding process with the similar level of concentration as in 
manual operation. Mechanized/automated systems rely on precision control of joint fit-up and welding conditions and tedious programming of welding parameters to produce repeatable results. However, precision control of joints and welding conditions is very costly and not always guaranteed. Up to date, there are no satisfactory sensors that can conveniently/ automatically monitor the penetration depth or the degree of the full penetration like a skilled welder. It is thus of great interest to develop the intelligent welding machines that can sense the welding process like the human welder yet do not suffer from the limitations of the human welder. In the following subsection the human welder's behavior is analyzed.

\subsection{Human welder's behavior}

The diagram of the human welder's behavior is shown in Fig. 2 [4]. Given a certain welding task, a human welder starts with some initial estimation input $I$ which may include the current, arc length, welding speed, etc. After the input of the initial control, the welder perceives necessary direct information $\Omega^{\prime}$ from the weld pool. $\Omega$ is the information that should be sensed from the welding process which is controlled by the welding parameters:

$$
\Omega=\gamma(I)
$$

The welder may derive indirect information $\Psi$ from the direct information:

$$
\Psi=\eta\left(\Omega^{\prime}\right)
$$

The instant state of welding process $\Phi$ may contain both the direct and indirect information of welding process.

The process evaluation involves the decision-making process. Given the inconsistent nature of human welder action, there may be certain inconsistency of welding performance even for a well-trained welder. The welder first maps the goals of the welding process $\Xi$ into the desired state of welding process $\Phi^{*}$ :

$$
\Phi^{*}=v(\Xi)
$$

Then the welder evaluates the desired and the instant state similarly like with some norm-based cost function, shown in (4):

$$
\varepsilon=\xi\left(\mid \Phi-\Phi^{*} \|_{n}\right)
$$

And the optimal state for the next instant $\hat{\Phi}$ can be considered to minimize the cost function:

$$
\hat{\Phi}=\left.\rho\left(\Phi, \Phi^{*}\right)\right|_{\min (\varepsilon)}
$$

Eventually, the welder performs a mathematic equivalence to mapping from the optimal state to the control:

$$
\Delta I=\omega(\hat{\Phi})
$$

The output execution may be considered to be perturbed by a white Gaussian noise $v$, which reflects the maneuver skill of the human welder. There exists a common pattern from the direct information $\Omega$ to the welder's output $I$ which is defined as the following equation:

$$
\Delta I=F(\Omega)
$$

The model of human welder's behavior (7) can be considered as the combination of the five elements from "Information perception" to "Output execution" in Fig. 2. It is possibly nonlinear and time-varying.

As has been discussed above, human welder has limitations such as inconsistent concentration, fatigue and stress.For the intelligent welding machine that mimics the human welder's intelligence, these limitations can be overcome. The illustration of intelligent welding machine can be observed in Fig.3. In this figure, the information perception block in Fig.2 is substituted with a vision-based sensing system. The output of the sensing system is the 3D coordinates of the weld pool surface. Like the human welder's ability to interpret the complex weld pool shape, intelligent welding machine will characterize the weld pool, and output certain characteristic parameters to the human intelligent model. The outputs of the human intelligent model are the welding inputs, and will be inputted into the welding process. 


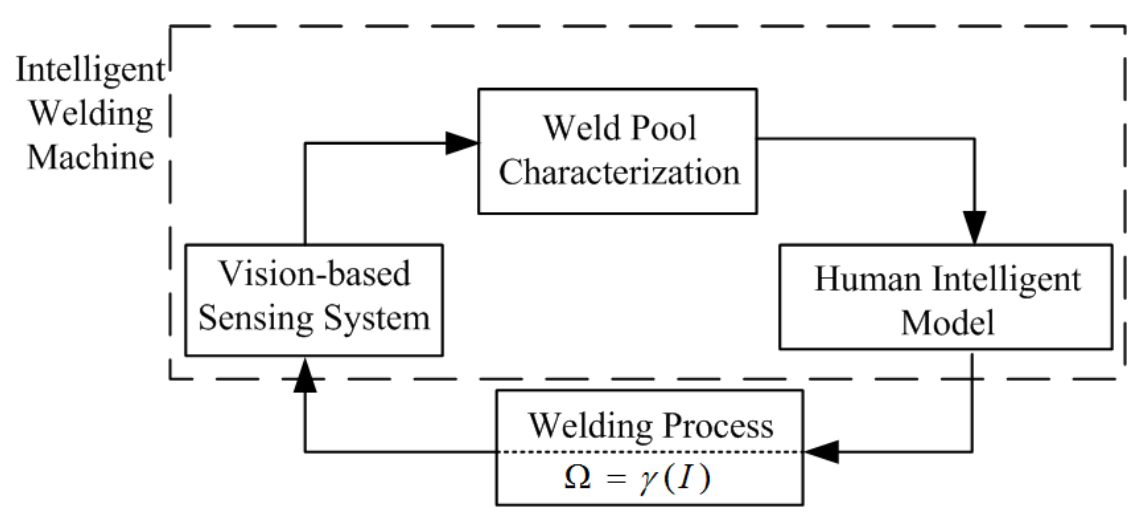

Fig. 3 Illustration of intelligent welding machine that mimics human welder's behavior.

This survey paper addresses the implementation of the intelligent welding machine, including vision-based sensing system, weld pool characterization, human intelligent model development, and closed-loop control experiments to verify the effectiveness of the intelligent human welder response model to achieve desired full penetration in GTAW. Specifically, section 2 surveys different sensing method of the weld pool, and introduced a novel 3D vision-based sensing system developed at University of Kentucky. Characterization of the weld pool is performed in section 3. Human intelligent model is constructed in section 4, including an extensive survey of the human dynamics and neuro-fuzzy modeling techniques. In section 5, closed-loop control experiments are performed to verify the effectiveness of the intelligent welding machine. Future research directions in this field are proposed in section 6.

\section{Sensing of the Weld Pool}

In manual welding, welders who observe the weld pool can assure the desired full penetration is produced. However, in mechanized welding, developing an accuratesensing system which can mimic the human welder's sensory capability is difficult. The difficulty is primarily due to the invisibility of the liquid metal bottom surface underneath the weld pool and the extreme brightness of the arc. Various methods have been studied, including pool oscillation, ultrasound, infrared sensor, and vision-based sensing method, etc. In the following subsections, the above mentioned sensing methodsare briefly surveyed.

\subsection{Pool Oscillation Method}

Weld pool can be brought into natural oscillation and the oscillation frequency of the weld pool is related to the weld pool geometry. This phenomenon may be used to monitor the weld pool in a feedback control system. The pioneering work in this area was conducted by Kotecki [6], and Richardson [7].Hardt [8] and their co-workers proposed a method to determine the back-side bead width by measuring the natural frequency of pool motion when driven by a time varying arc plasma force. G. den Ouden $[9,10]$ further found that an abrupt change in the oscillation frequency of the pool during the transition from partial to full penetration. A synchronous weld pool oscillation method for controlling the weld pool dimensions and state of penetration was developed by Andersen [11]. Ju [12] proposed a new vibration method: the Pulse Shielding Gas (PSG) oscillating method. Yudodibroto [13] implemented the weld penetration control based on weld pool oscillation sensing method during GTAW process with cold filler wire addition. It was found that the weld pool oscillation approach is suitable for penetration control during cold wire GTAW when the metal transfer occurs in an uninterrupted bridging manner.

\subsection{Ultrasonic Sensing Method}

Ultrasonic sensors [14-20] are widely used to determine the boundaries of the liquid and metal in the weld 
pool.In [15] the developed ultrasonic sensing system could locate and track the welding seam ensuring correct positioning of the welding head relatively to the joint preparation. At Georgia Institute of Technology, Ume $[16,17]$ developed non-contact ultrasonic penetration sensors based on laser-phased array techniques. Recently various non-contact ultrasonic sensing methods have been developed, such as laser ultrasonic sensing [14, 20], electromagnetic acoustic transducer (EMAT) ultrasonic sensing [15], laser-EMAT ultrasonic sensing [19], etc. Mi[20] further developed a sensing system to monitor the weld penetration. The sensing system was based on using a laser phased array technique to generate focused and steered ultrasound, and an electromagnetic acoustic transducer (EMAT) as a receiver.

\subsection{Infrared Sensing Method}

Infrared sensing is a type of non-contact thermal measurement technique which has been widely used in various applications. Because the temperature distribution in the weld zone contains abundant information about the welding process, infrared sensing of welding processes has drawn attentions from various research institutions. Chin [21-24] developed a thermal imaging system to measure the variations in weld process parameters such as bead width, penetration depth, and torch offset. The penetration depth has been correlated with the infrared characteristics of the infrared image. The interference of arc radiation was reduced by selecting scanner with specific wavelength region. At MIT, Hardt used an infrared camera to view the temperature field from the back-side [25]. The penetration depth was precisely estimated from the measured temperature distribution and then controlled [26]. In [27] infrared sensor was used to monitor weld process parameters including weld bead width, penetration depth, and torch position. Analysis of the computed ellipse showed that the temperature gradient or heat energy distribution (minor axis of the ellipse) and the heat input (volume under the temperature profiles) varied with the penetration depth.

\subsection{Vision Based Method}

Skilled welders can assure the desired full penetration based on their observation of the weld pool. The weld pool should thereforecontain abundant information about the weld penetration. Vision-based systems have been applied to monitor the weld pool emulating human welders' visual sensory ability. In the following subsections, vision-based sensing methods are extensively reviewed, including 2D weld pool sensing, and 3D weld pool sensing methods.

\subsubsection{D Weld Pool Sensing}

2D weld pool geometry contains certain information of the welding process, and has been used to monitor the welding process and control the weld penetration [28-30]. Fan et.al [29] studied 2D visual sensing and penetration control in aluminum (Al) alloy pulse GTAW process. In [30] two normal CCD cameras were used to capture clear images from two directions: one of them was used to measure the root gap and another one is used to measure the geometric parameters of the weld pool.

\subsubsection{D Weld Pool Sensing}

Although 2D weld pool geometry has been obtained with above different techniques, the convexity/deformation of the weld pool is not yet fully explored. Early researchers have found that important information such as weld defects and penetration are contained in the surface deformation of the weld pool [31, 32]. Compared with the 2D weld pool geometry, the 3D geometry can better predict the weld penetration which is measured by the backside weld bead width [33]. Numerous methods have been developed to reconstruct the 3D weld pool surface.

The measurement of general 3D surface has been recently studied extensively with techniques which can be roughly categorized into three branches: 1) reflectometry / deflectometry with fringe reflection technique [34-36]; 2) phase shifted digital fringe projection technique for diffuse objects [37, 38]; 3) shape from shading technique [39]. Unfortunately, the dynamic and specular nature of the weld pool and the interference 
from the strong arc radiation complicate the observation and deteriorate the effectiveness of most of those methods.

Specifically for the 3D weld pool measurement, the most popular techniques currently being studied can be divided into four categories:

\section{- Model-based reconstruction}

The 3D weld pool surface was partially reconstructed based on a simple model proposed in [40]. The reconstruction algorithm was further applied in [41] for the control of weld pool shape. A fuzzy logic controller was constructed to control weld penetration. Although the model-based reconstruction algorithm is simple and fast, it can only measure the height of the weld bead that is solidifying or have already solidified at the rear of the weld pool. The 3D geometry of head of the weld pool cannot be acquired using this method.

\section{- $\quad$ Stereovision measurement}

In [42], two cameras were synchronized to capture the two images of weld pool surface simultaneously in the short circuit period during the Surface Tension Transfer (STT) process and external illumination was used. The paired images were rectified using calibration parameters obtained through the stereo calibration procedure. Then by using stereo image processing algorithms the weld pool shape was rendered in 3D. A closed-loop control system was further developed using the technique for robot welding process [43]. However, the shape of the bright part in the head of the weld pool cannot be acquired by using this method. Further, the accurate reconstruction of the weld pool requires both precise synchronization of the two cameras and high quality of the captured images.

To avoid the synchronization problem, the biprism stereo vision sensing was proposed in which one camera was used with a biprism attached on its head [44]. However, only the height of the weld pool boundary was extracted in real-time, the 3D geometry inside the weld pool was missed. A similar reconstruction algorithm has been utilized in a stereo sensing system using single camera with a stereo adapter developed to reconstruct the 3D weld pool for tracking particle flow on the weld pool surface [45].

\section{- Shape from shading reconstruction}

3D weld pool reconstruction algorithms have also been proposed based on shape from shading method [46-50]. Zhao et al. [49] used this algorithm to reconstruct the surface from one single weld pool image. The extracted three-dimensional parameters for the weld pool surface were verified and used for double-sided shape control. However, the algorithms are usually complex and thus used for off-line reconstruction of the 3D weld pool surface. Furthermore, the reconstruction algorithms using shape from shading are based on two assumptions: 1) The object surface is a Lambertian surface which reflects light with equal intensity in all directions; 2) The camera and the light source are at the infinite far distance from the object surface, while the weld pool is a specular surface which is not a Lambertian surface. The camera and light source in the experiment systems are not far enough from the weld pool such that the infinite far position assumption is invalid. Therefore, the 3D weld pool reconstruction using shape from shading might not be an ideal solution.

\section{- $\quad$ Structured-light based sensing}

A structured-light vision system was developed in [51] projecting a pulsed laser on the weld pool surface through a special grid. A high shutter-speed camera was used to capture the laser stripe pattern reflected by the weld pool surface. However, the synchronization of the laser and high-speed shutter required specific, high-costly, and sophisticated equipment. The boundary of the weld pool is also hard to extract using this sensing method.Follow-up study [52] provided a measurement system based on a 
mathematical model of weld pool surface. Although this work did not propose a new reconstruction algorithm, it provided some novel insights of 3D weld pool surface measurement.A laser grating sensing technique was proposed in [53]. The reflected grating was captured by a two-lens system. The depth of weld pool was determined based on the phase changes of the deformed grating image [54]. However, using this method the boundary of the weld pool was hard to be determined. A novel reconstruction algorithm using the slope field and point tracking of the dot matrix has been proposed in [55]. A laser pattern reflected from the weld pool surface has been intercepted/imaged by/on a diffusive imaging plane placed with a distance from the weld pool [56]. The camera aims at the imaging plane (rather than the weld pool illuminated by the extremely strong arc) to acquire the reflected laser pattern. Its uniqueness lied in its simultaneous use of the distance and specular nature of the weld pool surface to significantly decay the arc radiation but not the intensity of the laser reflection from the specular weld pool surface despite the distance. However, this slope error based algorithm requires numerous iterative loops till the estimated surface approaches the actual weld pool surface resulting in relatively large reconstruction errors. Similarly, this imaging method and reconstruction algorithm have been used to image and reconstruct the weld pool surface in gas metal arc welding (GMAW) using a five line laser pattern [57].

\subsection{D Vision-based Weld Pool Sensing System [33]}

In order to capture the geometric information of the weld pool in three dimensions, a 20mw illumination laser generator at a wavelength of $685 \mathrm{~nm}$ with variable focus is used to project a 19-by-19 dot matrix structured light pattern (LasirisSNF-519X (0.77)-685-20) on the weld pool region. Part of the dot matrix projected inside the weld pool is reflected by the specular weld pool surface. Because of the plasma impact, the surface of the weld pool is depressed and distorted in GTAW. Therefore, no matter which shape (concave or convex) the weld pool presents, the alignment of the reflected laser dot matrix is distorted by the deformed specular weld pool surface. The distortion of the reflected dot matrix is determined by the shape of the threedimensional weld pool surface and thus contains the 3D geometry information about the weld pool surface.

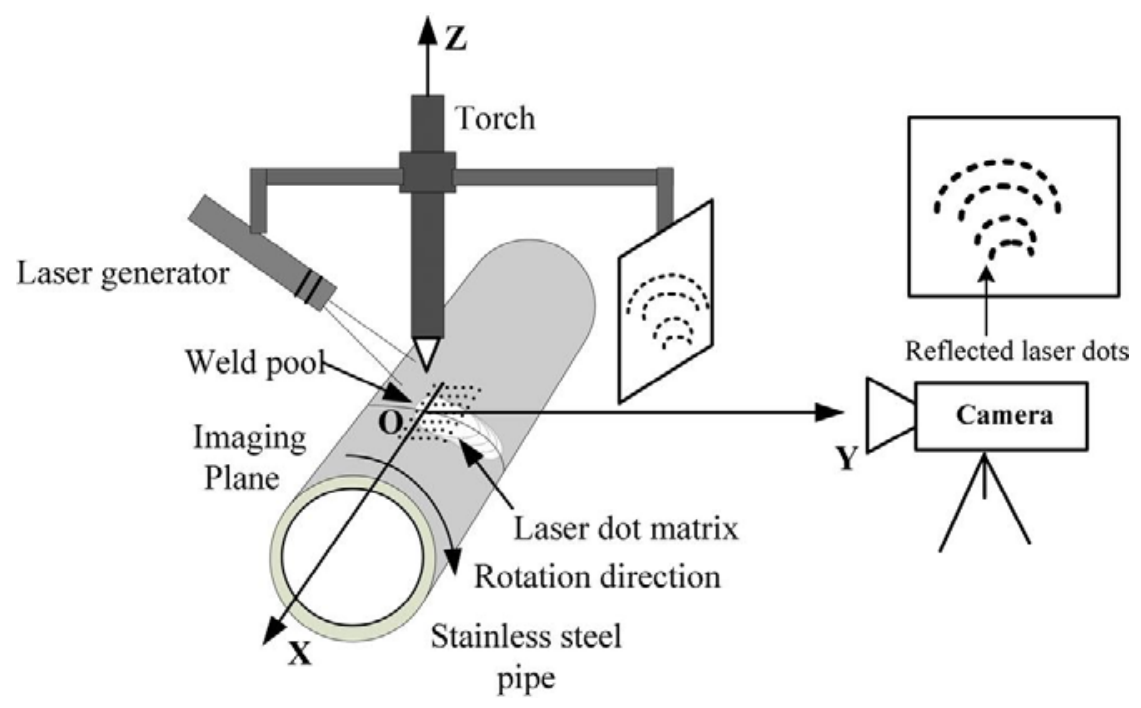

Fig. 43D vision based weld pool monitoring system [33]

In order to capture the image of the reflected dot matrix from the weld pool, animaging plane is installed with a distance about $100 \mathrm{~mm}$ from the torch. A camera is located behind the imaging plane directly aiming at it. The camera captures the images of the reflected laser dot matrix from the imaging plane with a 
resolution 640-by-480. A band-pass filter matched with the laser wavelength is attached to the camera. A computer connects with the camera using a 9-pin 1394b interface. With a max frame rate $200 \mathrm{fps}$ at the resolution 640-by-480, the high transfer rate for camera to PC (800M/s maximum) makes possible the realtime monitoring and measurement of front side weld pool geometry in the GTAW process. By specific image processing and reconstruction algorithms [56], the weld pool geometry including the boundary and the threedimensional surface shape is obtained.Taking Fig 3(a), an acquired image in the imaging plane, as an example, the results of image processing and reconstruction are shown in Fig 3(b) to Fig. 3(f). The time cost for the image capturing, processing and the weld pool reconstruction is about $30 \mathrm{~ms}$ which is fast enough to monitor the weld pool dynamics in GTAW.

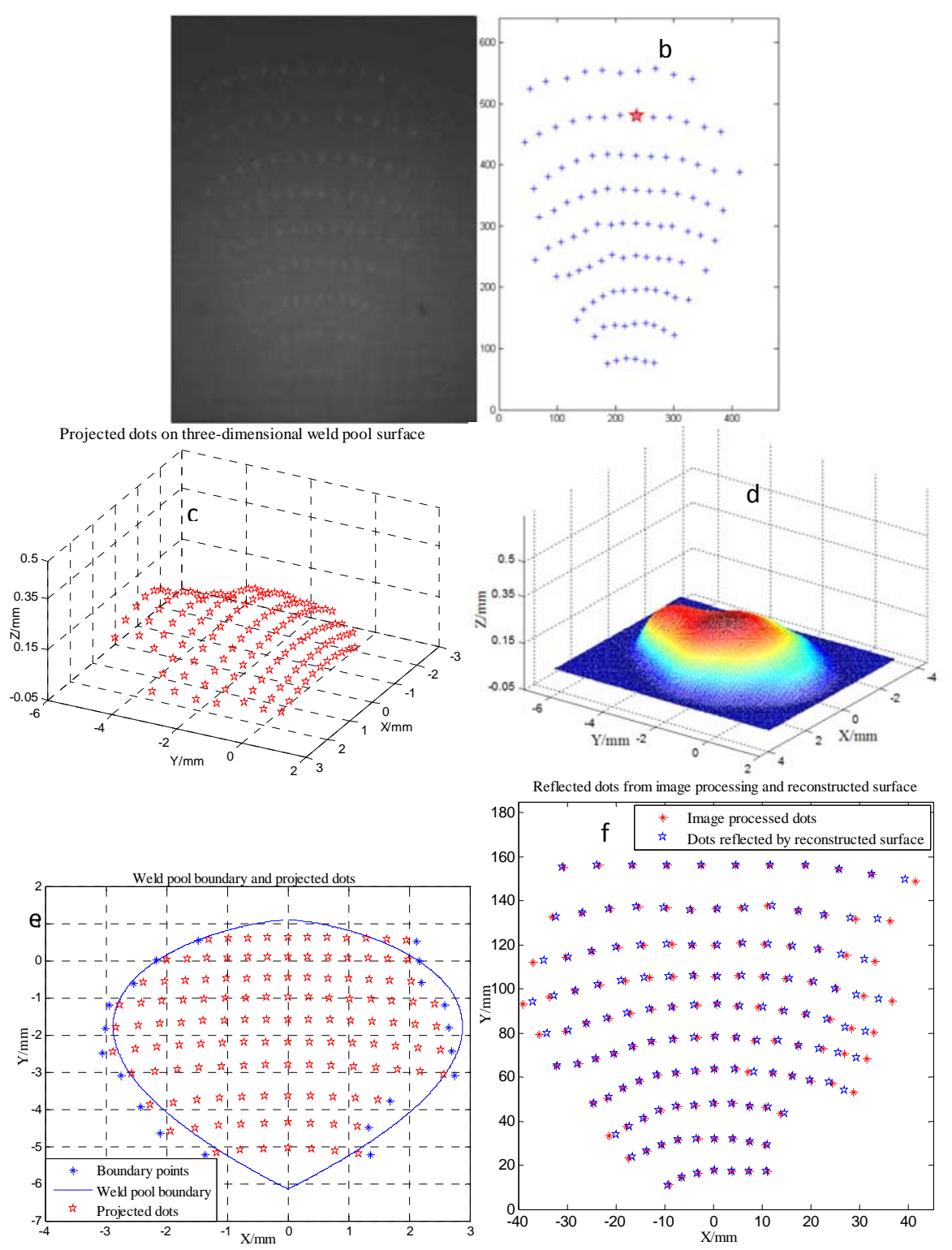

Fig. 5 Results of image processing and three-dimensional reconstruction [5].(a) Captured image using the sensing system; (b) Resultant dots in the captured image using image processing; (c) Projected dots on the 3D weld pool surface; (d) Interpolated 3D weld pool surface ; (e) Weld pool boundary and the projected dots; (f) Measured and calculated reflection pattern. 


\section{Characterization of the Weld Pool}

The ability to directly monitor the weld pool surface detailed in previous subsection represents a major progress toward next generation intelligent welding because the weld pool surface should contain sufficient information to determine the weld joint penetration as skilled human welders can. However, for a machine to be able to use the weld pool surface to determine the weld joint penetration, characteristic parameters should be used rather than the large set of 3D coordinates. These characteristic parameters should keep the fundamental information in the weld pool surface about the weld joint penetration.

In order to obtain the optimal characteristic parameters, various experiments under different welding conditions have been performed to produce full penetration welds with different back-side bead widths and acquire corresponding images used to reconstruct the weld pool surface and calculate candidate characteristic parameters [33]. The experiments have been designed to produce acceptable distributions for the candidate characteristic parameters in order to ensure the validity of the resultantmodels. Five candidate characteristic parameters are proposed: weld pool width, length, area, interception area, and convexity. Fig. 6 shows the illustration of the weld pool characteristic parameters proposed in [33]. After the weld pool boundary is acquired, the weld pool width and length can be straightforward to obtain. The convexityis defined as the intercepted area divided by the length of the weld pool (i.e., the average height of the weld pool).
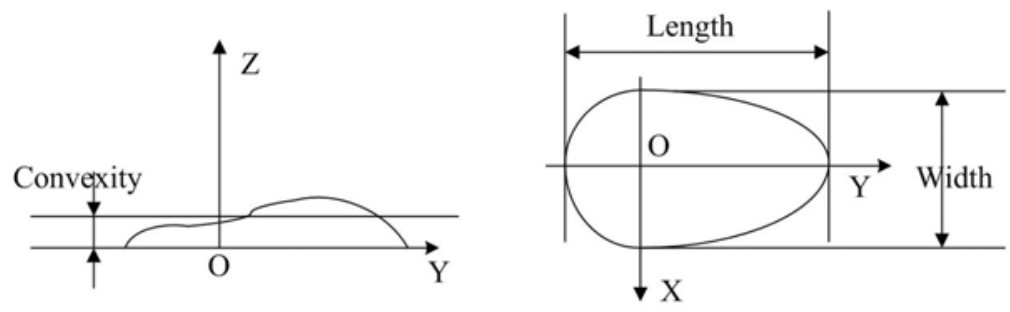

Fig. 6 Weld pool characteristic parameters

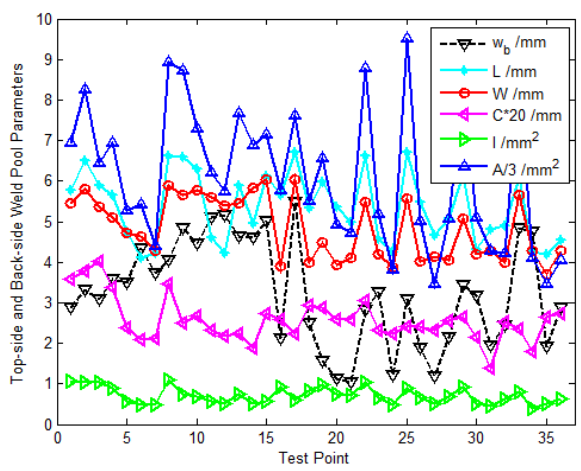

(a)

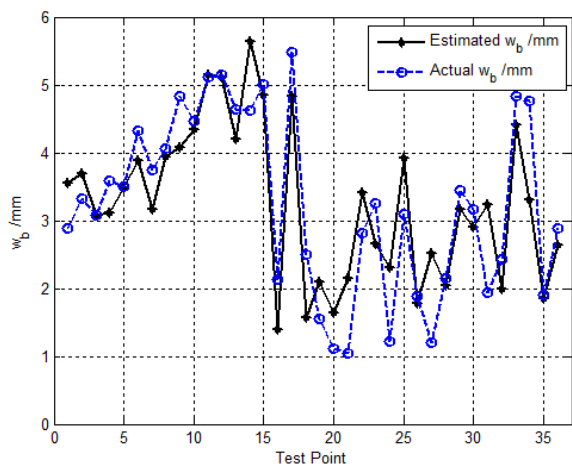

(b)

Fig.7(a) Measured 3D weld pool surface parameters from 36 experiments (b) Least squares model fitting with 3-parameter model using the width, length, and convexity.

Fig.7(a) shows the experimental data in 36 experiments.Through the least squares algorithm based statistic analyses, it is found that the width, length, and convexity of the 3D weld pool surface provides the optimal model to predict the back-side bead width with an acceptable accuracy. The estimation results are plotted in Fig.7(b) and The 3-parameter optimal model identified is [33]: 


$$
w_{b}=1.7906 W-0.5657 L-10.8057 C-0.9868
$$

Using these characteristic parameters, the back-side bead width can be determined using the parametric model (8) with an acceptable accuracy. The parametric model (8) and characteristic parameters thus adequately extracted the information contained in the large set of 3D coordinates for the sample points on the 3D weld pool surface and made it possible to use the weld pool surface to determine and control the weld joint penetration and emulate the intelligence of a skilled welder.

\section{Modeling of the human welder}

In this section modeling of the human welder is presented, including an extensive survey of the human dynamics and neuro-fuzzy modeling techniques.

\subsection{Human response modeling}

Despite the trend of growing automation degree in industrial processes and machines, the human operator/controller is still irreplaceable in various applications. What makes the identification of human operators' behavior such as a challenging endeavor is that the human operator is a nonlinear, often timevarying controller whose coefficients might vary rapidly with factors such as motivation, workload, fatigue, and other physiological variations [65, 68]. Specifically in welding operations, a welder makes decisions primarily based on past learned experiences/skills which might not involve a fundamental understanding of the laws of welding physics. Also, a human welder assesses and controls a welding process using a humanistic approach where the feedback sensory information acquired by the welder might be imprecise and only reflects partial truths about the instant status of the weld process.

Modeling and identifying the dynamics of a human controller/operator originated from the theories of servomechanism and filtering in the 1940's. The research made great strides in the late 1960's and 1970's. A series of preliminary experiments were conducted on human tracking in one-dimensional compensatory task [58]. McRuer and Jex conducted a systematic measurement of the human operator with a variety of controlled system dynamics and random-appearing inputs of different bandwidths [59,60]. A crossover

model of human operator was proposed that can describe the linear portion of the human operation in a single-loop compensatory task in a frequency range around crossover frequency.

Optimal control theory was then introduced in human operator behavior identification [61]. It was based on an assumption that the well-trained human operator behaves in a nearly optimal manner subject to the inherent physio-physical limitations. Based on the assumption, an optimal control model (OCM) was proposed in 1970 on the dynamic characteristics of a pilot[62].The transfer function was considered as the cascaded of the inherent part of reaction time delays and lags attributed to the neuromuscular system and the equalization part adjustable to the task requirement, where the time delay comes from the various internal time delays associated with visual, center processing, and neuro-motor pathways.

The OCM was later extended by Tomizuka to cover preview tracking [63, 64]. In addition, a modified optimal control model (MOCM) was proposed by Davidson and Schmit in 1992 [71]. The MOCM replaced the time delay of the OCM with a Pade approximation that allowed one to obtain a soletransfer function representation of the operator. Many researchers have continuously studied the tracking ability and characteristics of the human operator as an adaptive controller [65], a tele-manipulator[66] or an optimal controller [67]. Unfortunately, these methods lead to typically high order for the obtained models. For instance, the order of these OCM-based models is equal to the sum of the orders of the controlled element, disturbance filter, neuro-motor lag and Pade delay. This feature makes insight into the operator control model difficult to determine. A fixed-order optimal control model based on MOCM was thus proposed to reduce 
the order while keeping the model optimality [72]. Nonlinear methods such as neural networks, neuro-fuzzy or adaptive models were employed as well to model the human actions [77-81].

The modeling of the human operator has been studied in the physiological perspective. Based on [73, 75], in the learning stage the cerebral cortex is playing the role of controller in the feedback path. In [74], the feedback error learning model was proposed. The model considered that the human hand/thumb motion skill comes from the feed-forward structure of the cerebellum representing the inverse model of the hand/thumb system. In addition, an iterative manual control model has been proposed based on human operator's physiological perspective [70]. A recalling factor has been introduced in the model representing the human operator's experiences/skills. The model indicates that human operators tune their control actions using error and error rate in each iteration.

A human operator intermittently scans the state of the controlled system and continuously operates. A skillful operation means that the information is scanned less frequently. A control action similar to the minimum attention [82] might be found in human operation. In addition to such minimum attention, Ito's observation in that if the operation skill level exceeds to a certain extent, the operation becomes of feed-forward type, can be interpreted as that the interval of the attention becomes longer as the skill becomes better. Therefore, for a skilled operator, the control action would tend to be feed-forward type, while an unskilled operator controls the system in a feedback close loop. Also, the observation of the system state might be achieved by the trigger of the special occasion of the event [83].

The delay in the human operation should be one of the important factors to study the stability of the human in the close-loop control system. Time-varying delay time of a human controller is studied in [69] in manual tracking tasks. A discrete time recursive delay identifier is proposed to estimate the fractional delay time by embedding the bilinear interpolation scheme in the extended Kalman filter. Yet, Kleinman [61, 62] stated that the delay from the visual perception to the neuro-motor pathway was not necessarily considered in human operation since a skilled human operator predicts that state. In addition, it is considered in [76] that the cerebellum has the function of the Simith Predictor which compensates the delay in the closed loop.

Although the nonlinear methods typically improve the prediction performance to some extent, it is still very appealing to use linear/hybrid models due to their convenience for analysis and design [84, 88, 89]. A new hybrid fuzzy-ARX modeling method has been developed for predicting the human operator control actions in [85]. A linear dynamic model was proposed based on stochastic switched dynamics in [86]. The motivation of the modeling is the observation that the operator appropriately switches some simple primitive skills which might be caused by human's decision making [87].

\subsection{Neuro-fuzzy Modeling}

This subsection introduces the basic definitions and concepts for neuro-network, fuzzy set, as well as neurofuzzy modeling technique.

Neural networks (NNs) approach has been widely used for regression, identification, system modeling and control applications in high-dimensional systems. Specifically, adaptive network is considered to be the unifying framework that subsumes almost all neural network paradigms with supervised learning capabilities [91]. It is a network structure consisting of nodes through links. Each node represents a process unit, and the links represents the causal relationship between the nodes. Parameters of the nodes / links are modifiable, making the network adaptive. The basic learning rule of the adaptive networks is steepest descent method [100]. Rumelhart et al. [101] utilized the method, also well known as "backpropagation learning rule", to find the gradient in a multilayer neural network.

Classical set is referred to a set with a crisp and unambiguous boundary. Although it is suitable for various applications, they do not reflect the natural abstract and imprecise human thoughts. A fuzzy set, is a set 
without a crisp boundary. It describes the transition from "belonging to a set" to "not belonging to a set" as a gradual and smooth membership functions, which gives fuzzy sets flexibility in modeling commonly used linguistic expressions [90].

Fuzzy inference system (FIS) is a computing framework based on fuzzy set theory, fuzzy if-then rules, and fuzzy reasoning [91]. It is also referred to as fuzzy-rule-based system [91], fuzzy expert system [92], fuzzy model [93, 94], fuzzy associative memory [95], fuzzy logic controller [96, 97, 98], and fuzzy systems. The basic structure of a FIS consists of three components: a rule base (a selection of fuzzy rules), a database (membership functions used in the fuzzy rules), as well as a reasoning mechanism (performs fuzzy reasoning based on the rules and derive a conclusion). There are several types of FIS, including Mamdani fuzzy inference system [98], Sugeno fuzzy model (or TSK fuzzy model) [93, 94], and Tsukamoto fuzzy models [99]. The differences between these FIS lie in the consequents of fuzzy rules, aggregation and defuzzification procedures.

In traditional fuzzy systems, membership functions are pre-determined by domain experts [102]. In these models, however, no systematic adjustments are made on the fuzzy rules, membership functions, or reasoning mechanism based on the behavior of the fuzzy system. Such fuzzy rules could be vague, misinterpreted, or incomplete, which may severely deteriorate the performance of the fuzzy systems. Therefore, it is tempting to apply optimization techniques to tune the parameterized membership functions for better fuzzy model performance.

Neuro-fuzzy approach (i.e. the fusion of the NNs and fuzzy logic) determines the parameters in fuzzy models using learning techniques developed in neural networks, and has been successfully applied in various areas [103-106]. Jang [107, 108] developed the Adaptive Neuro-Fuzzy Inference System (ANFIS) by using a hybrid learning procedure. Recently, ANFIS has been employed to model nonlinear functions, identify nonlinear components in control systems, and predict chaotic time series [109-111].

\subsection{Neuro-fuzzy based human welder response modeling results and analysis [112]}

In order to model the human welder's adjustment of current in response to the weld pool geometry during full penetration process, a manual control system is developed combining the sensing system with a manual control mechanics, as is shown in Fig.8 [112].

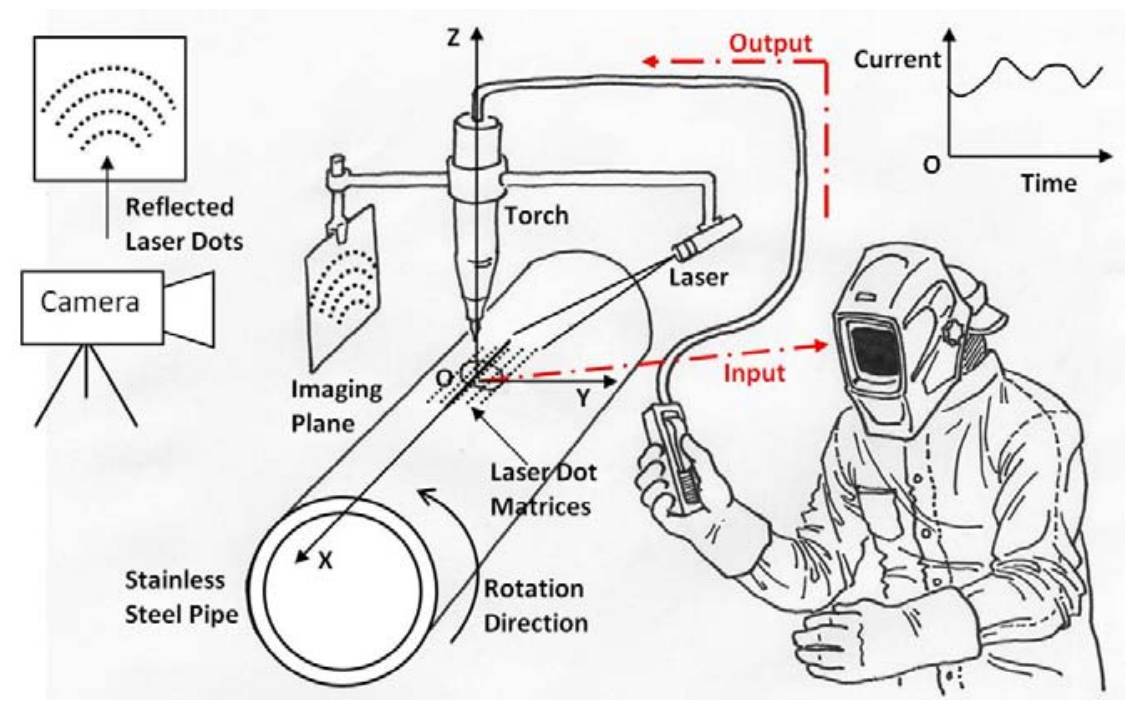

Fig.8 Manual control system of GTAW process [112]. 
In this system the human welder holds the current regulator while observing the geometry of weld pool and adjusts the welding current accordingly in an effect to control the weld joint to full penetration. Nine dynamic experiments are conducted. In experiments 1 to 3 the weldingspeed is designed to vary within reasonable ranges $[1 \mathrm{~mm} / \mathrm{s}, 2 \mathrm{~mm} / \mathrm{s}]$ in order to change the weld pool geometry. Then the human welder adjusts the current to maintain the same penetration state after the change of the welding speed.The arc length is set to $3.5 \mathrm{~mm}, 4.5 \mathrm{~mm}$, and $5 \mathrm{~mm}$ for these three experiments, respectively. In experiments 4 to 9 the arc length is varying from $3 \mathrm{~mm}$ to $5 \mathrm{~mm}$, and the human welder adjusts the current in response to the fluctuations of the weld pool. The welding speed in these six experiments are $1 \mathrm{~mm} / \mathrm{s}$. The dynamic variation of weld pool geometry and the adjustment of current by the human welder are recorded respectively.Fig. 9 plots the measured input parameters (the weld pool width, length, convexity) and human welder outputs (the current). It can be seen from Fig. 5that the tendency of current adjustment is roughly opposite to the length and width fluctuation. The trend of convexity basically coincides with the current variation. The variation of the geometry and the current indicates the human welder reduces the current as the weld pool length or width raises, and increases the current as the weld pool convexity raises.

During the welding process, the human welder always scans the weld pool with a certain frequency regardless of the welder's eye blink. The frequency is $2 \mathrm{~Hz}$ in this study. Theoretically, the human welder's response should be determined by several weld pools over a time interval, rather than a single pool at an instant. However, if the weld pool does not change rapidly, the weld pool at an instant can be a good approximation over the interval. There is also a finite time-delay existing in the linear model of the human welder's behavior as a result of the neuromuscular and central nervous latencies.Based on the step response experiments it is observed that the average time delay of the welder's response is approximately $1.5 \mathrm{~s}$, or 3 sampling periods.

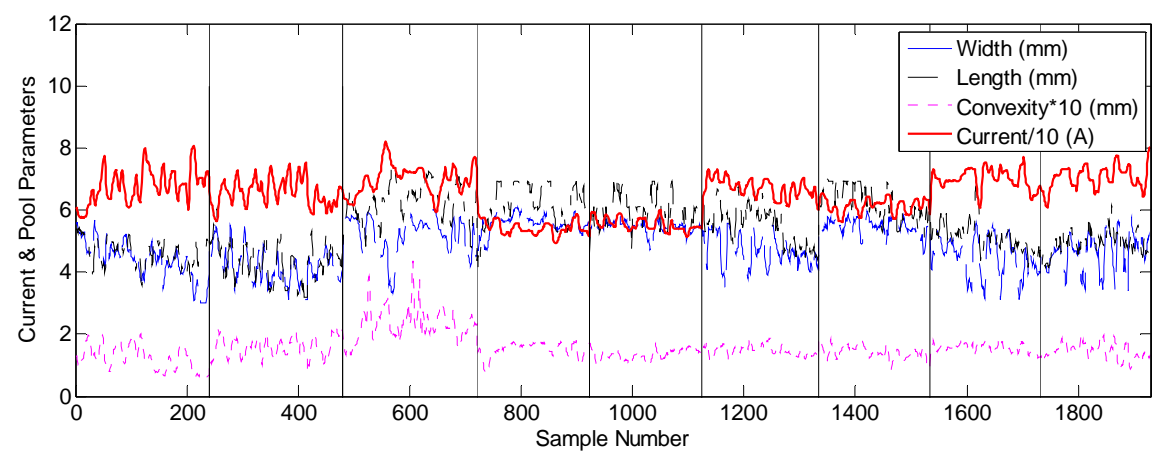

Fig.9 Measured weld pool parameters (width, length, convexity) and human welder's adjustments on current from nine dynamic experiments [112].

The novice welder's response contains high frequency adjustments caused by the novice maneuver skills of the human welder (Fig.9 with abrupt current adjustments). Spectral analysis of the human welder's response plotted in Fig.10 also indicates that the novice human welder's response concentrates on the frequencies under $0.3 \mathrm{~Hz}$ yet noticeable energy exist in high frequencies (above $0.5 \mathrm{~Hz}$ ).A output execution filter should first be employed before calculating the current adjustments and the modeling procedure to filter the high frequency improper execution of the novice human welder. 


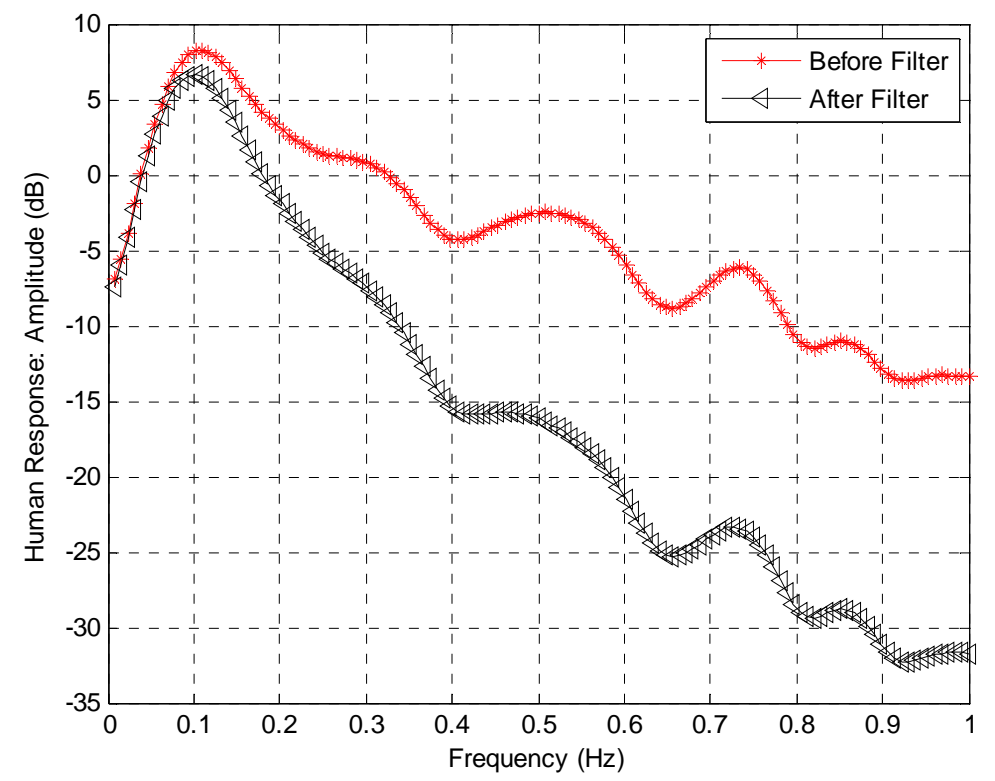

Fig.10 Spectral analysis of the human welder's response [112].

The designed low pass filter can be expressed as [112]:

$$
I_{f}(k)=\alpha_{f o} I_{f}(k-1)+\left(1-\alpha_{f o}\right) I(k)
$$

where $I_{f}(k), I_{f}(k-1)$ are the filtered currents at instant $k$ and $k-1$, respectively, and $I(k)$ is the current at instant k. $0<\alpha_{f o}<1$ is the coefficient of the filter, which should be a tradeoff between the filtering effect and response speed.

Calculated filtered current adjustments in nine experiments are plotted in Fig.11. As can be seen the abrupt changes of the current adjustments have been reduced and can thus better represent the correct human welder's response. The filtered adjustments will be used as model output in the following part.

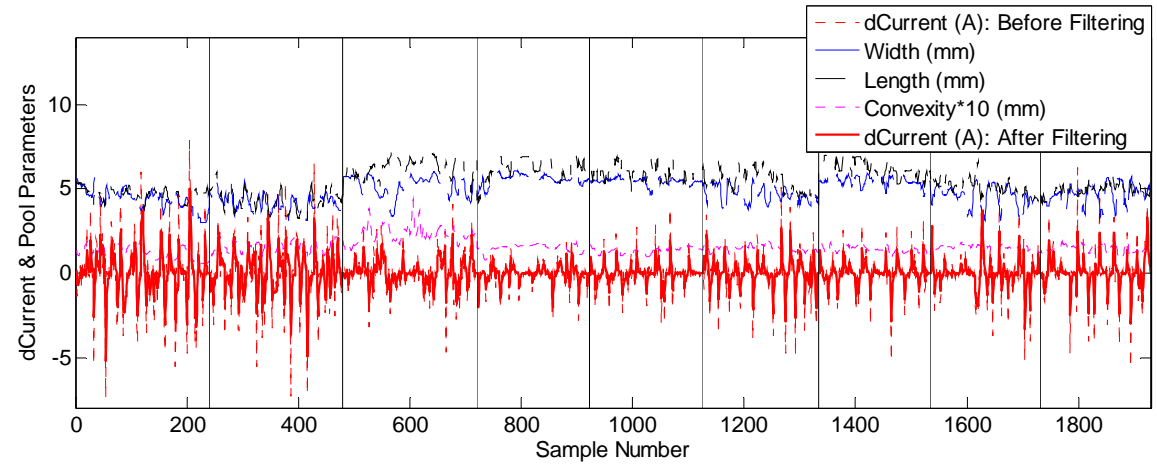

Fig.11 Original current adjustments and filtered current adjustments by the designed improvement filter in nine dynamic experiments [112]. 
In general, the human intelligent model can be written as:

$$
\Delta I(k)=f(W(k-3), L(k-3), C(k-3), \Delta I(k-1))
$$

The simplest form of (10) can be expressed by the following linear model [112]:

$$
\Delta I(k)=\alpha_{1} W(k-3)+\alpha_{2} L(k-3)+\alpha_{3} C(k-3)+\alpha_{4} \Delta I(k-1)
$$

Using the standard least squares method the linear model can be fitted from the raw data. The identified model is [112]:

$$
\Delta I(k)=-0.0492 W(k-3)-0.0049 L(k-3)+1.7348 C(k-3)+0.7155 \Delta I(k-1)
$$

The estimation results are shown in Fig.12. It can be observed that the current adjustments can be predicted with reasonable accuracy. However, noticeable fitting errors are observed when the current adjustments are relatively large. The maximum model error is $4.1707 \mathrm{~A}$, and the RMSE is $0.6042 \mathrm{~A}$.

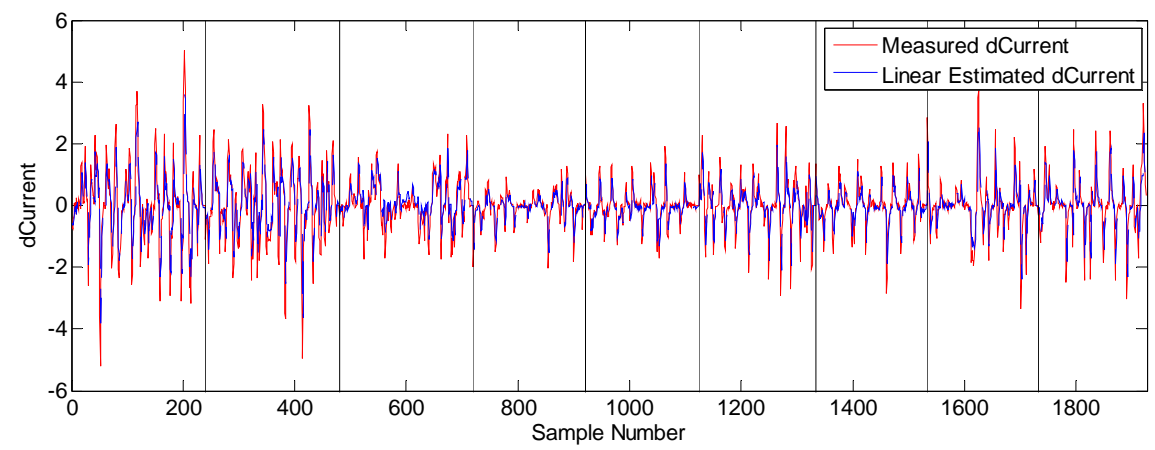

Fig.12 Linear modeling result in nine dynamic experiments [112].

In order to further improve the modeling accuracy and better model the inherent fuzzy inference mechanism of the human welder, human intelligence model (10) is realized using an ANFIS nonlinear model. The estimation result is plotted in Fig.13. The fuzzy input variables are partitioned by 2, as can be seen in Table I. It is noted that the ANFIS adopted in this study has 4 inputs, with 2 membership functions assigned to each input. Each generalized bell shaped membership function contains 3 parameters, totaling24 premise parameters. There are 16 fuzzy rules, resulting in 80 consequent parameters. Thus the total number of fitting parameters is 104. Hence, the data sets (11) with $\mathrm{N}=1926$ is enough for ANFIS model identification.The resultant model RMSE and maximum model error are $0.5710 \mathrm{~A}$, and 3.8277A, as are listed in Table II. Both the RMSE and maximum model error are improved by the ANFIS model.

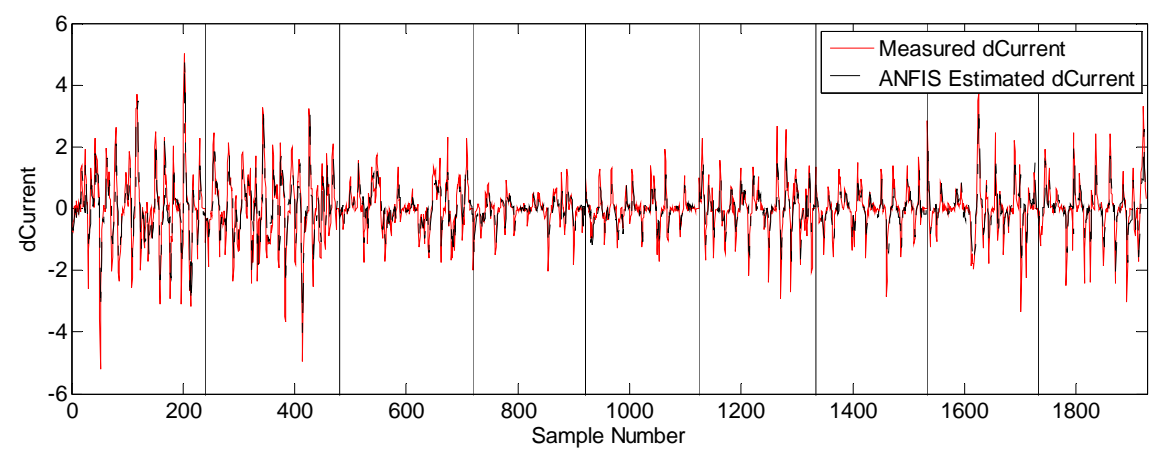

Fig.13 ANFIS modeling result in nine dynamic experiments [112]. 
TABLE I

PARTITION OF FUZZY INPUT VARIABLES

\begin{tabular}{|c|c|c|}
\hline Fuzzy Variables & $\begin{array}{c}\text { Number of } \\
\text { Fuzzy Sets }\end{array}$ & Partition \\
\hline Width & 2 & wide, narrow \\
\hline Length & 2 & long, short \\
\hline Convexity & 2 & large, small \\
\hline dCurrent $_{p}$ & 2 & large, small \\
\hline
\end{tabular}

TABLE II

Model CoMPARISON BETWEEN NEURO-FuZZy MODEL AND LINEAR MODEL [112]

\begin{tabular}{|c|c|c|}
\hline & RMSE /A & $\begin{array}{c}\text { Maximum Model } \\
\text { Error /A }\end{array}$ \\
\hline Linear Model (4 Inputs) & 0.6042 & 4.1707 \\
\hline ANFIS Model (4 Inputs) & 0.5710 & 3.8277 \\
\hline
\end{tabular}

Due to the consistency of the human welder's performance, the obtained model should have similar performance to predict the current adjustments in other welding experiments. To further verify the model, two verification experiments are conducted. In verification experiment 1 , the welding speed is designed to vary from $1 \mathrm{~mm} / \mathrm{s}$ to $2 \mathrm{~mm} / \mathrm{s}$ and the human welder adjusts the current in accordance to the varying weld pool geometry. The arc length is set at $4 \mathrm{~mm}$. In verification experiment 2 , the arc length is varying from $3 \mathrm{~mm}$ to $5 \mathrm{~mm}$ and the human welder adjusts the current accordingly. The welding speed is set at $1 \mathrm{~mm} / \mathrm{s}$. As can be observed in Fig.14(a)(b), the ANFIS model can estimate the welder's response in good accuracy for varying welding speed and arc length.

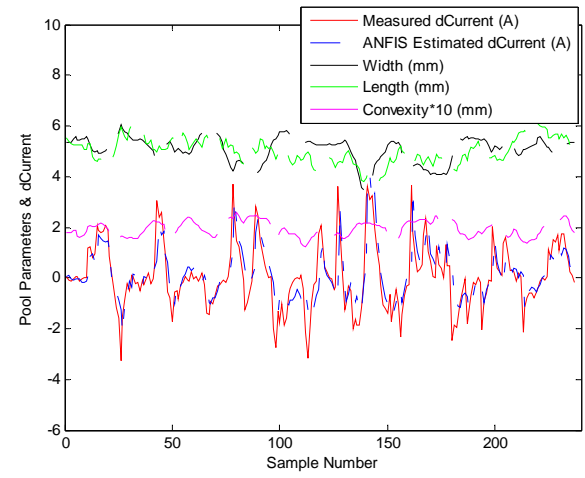

(a)

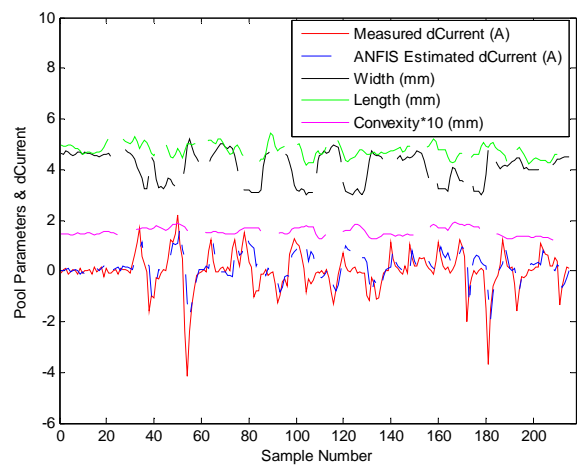

(b)

Fig. 14 (a) Verification experiment 1. The welding speed is varied from $1 \mathrm{~mm} / \mathrm{s}$ to $2 \mathrm{~mm} / \mathrm{s}$. The arc length is set at $4.0 \mathrm{~mm}$. (b) Verification experiment 2. The arc length is varied from $3 \mathrm{~mm}$ to $5 \mathrm{~mm}$. The welding speed is set at $1 \mathrm{~mm} / \mathrm{s}$ [112].

\section{Closed-loop control experiment}

The dynamic nonlinear ANFIS model will be utilized as a controller in automated GTAW process to maintain a consistent full penetration as a mimic of the human welder's intelligence and decision making capacity. The developed closed-loop control system is illustrated in Fig. 15 [112]. The sensing system is the same as that in Fig.2. A computer connected to the camera processes the captured image, reconstructs the weld 
pool, and extracts three characteristic parameters of the weld pool (the width, length, and convexity) in realtime. The human intelligence model then output the current. To imitate the welder's behavior as the human welder's response principle detailed in Section 2, in each experiment an initial welding input is first applied for the weld pool grows to full penetration, then the control of the human intelligence model starts.

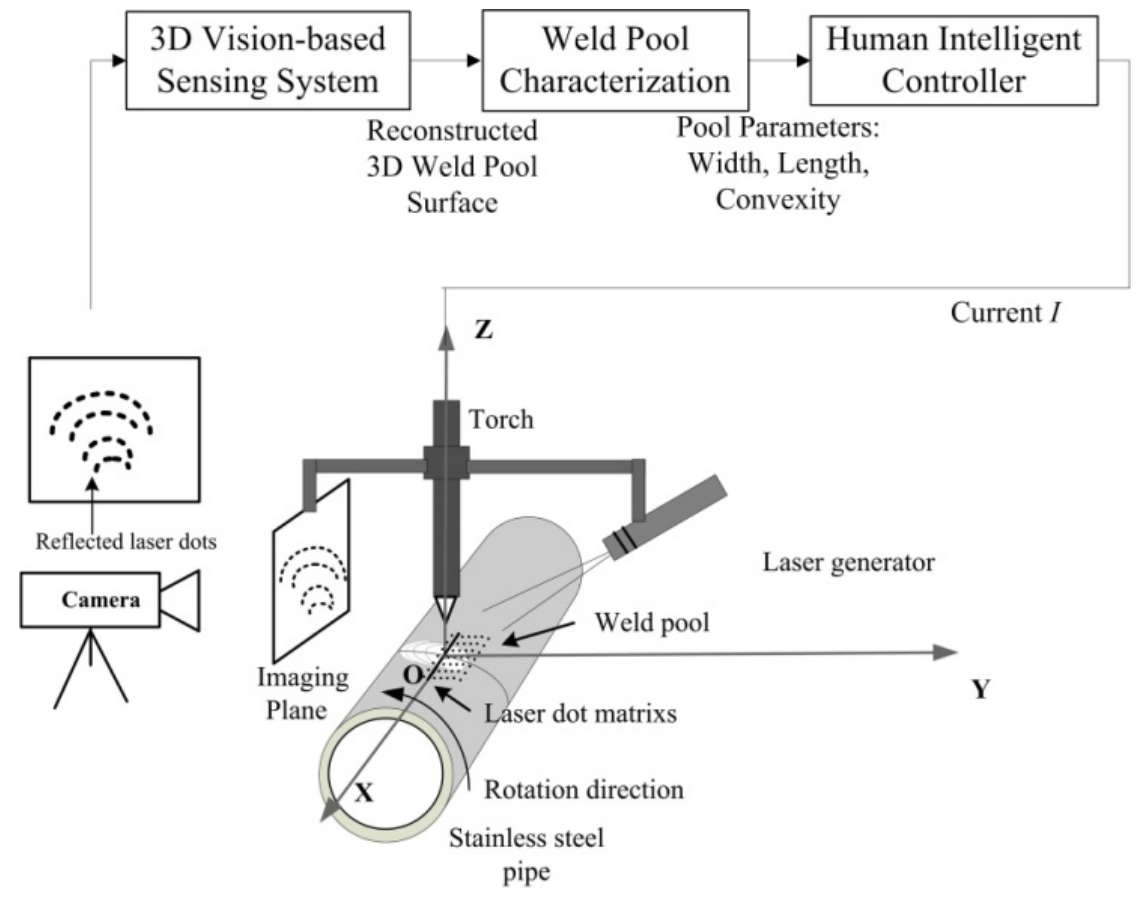

Fig.15 Experimental Set-up [112].

To confirm its effectiveness in controlling the process to achieve the desired weld penetration, various experiments have been designed and conducted in this section using this improved system to examine its performance/robustness under different welding conditions and initial welding currents [112]. In this section the controller's performance against welding speed variation is illustrated. The welding speed is designed to vary within the range from $1 \mathrm{~mm} / \mathrm{s}$ to $1.25 \mathrm{~mm} / \mathrm{s}$ and the human intelligence model is utilized to robustly control the welding current to maintain a uniform penetration.

It is observed from the welding experiments that the current adjusted by the human intelligence model fluctuates, resulting in noticeable oscillations of the backside bead width. This fluctuation of the current adjustments is understandable since the model is developed using the data from the behavior of a novice welder with limited skills. It is a common welding scenario that an unskilled welder cannot predict the process quickly and accurately so that overestimation and underestimation is frequently observed. However, a skilled welder can easily avoid the fluctuations by smoothing the behavior on the current adjustment. In this sense, a low-pass improvement filter similar to (2) is designed to filter the possible high frequency noise. The filter coefficient is selected to be 0.5 as a good tradeoff between smoothing effect and quickness of the controller response.

In arc welding, the welding speed is a major factor which influences the heat input into the process and has great impact in the weld penetration. In this experiment a step change of the welding speed is applied to examine the robustness of the controller over varying traveling speed. During the first $53 \mathrm{~s}$, the traveling speed is $1 \mathrm{~mm} / \mathrm{s}$. Then the speed is changed to $1.25 \mathrm{~mm} / \mathrm{s}$. As can be observed from Fig. 16(b), the weld pool width and length immediately decreases due to the step change of the speed. The controller is able to increase 
the current according to this abrupt change in the weld pool and tries to maintain a constant full penetration. As can be seen in Fig. 16(a), the current increases from 60A (when the traveling speed is $1 \mathrm{~mm} / \mathrm{s}$ ) to about 67A (when the traveling speed is $1.25 \mathrm{~mm} / \mathrm{s}$ ). As a result the backside bead width is maintained to about $5 \mathrm{~mm}$.

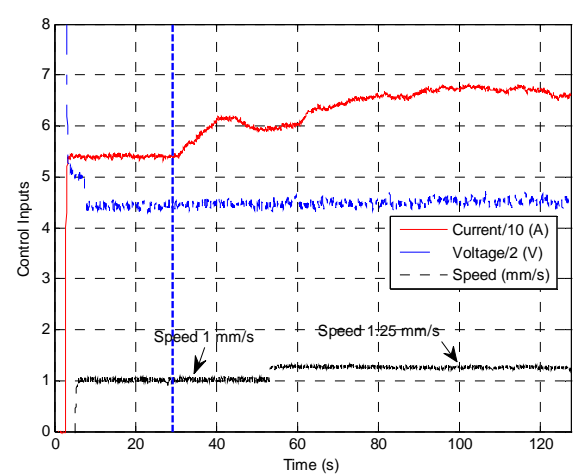

(a)

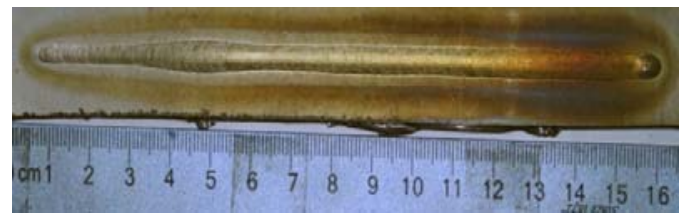

(c)

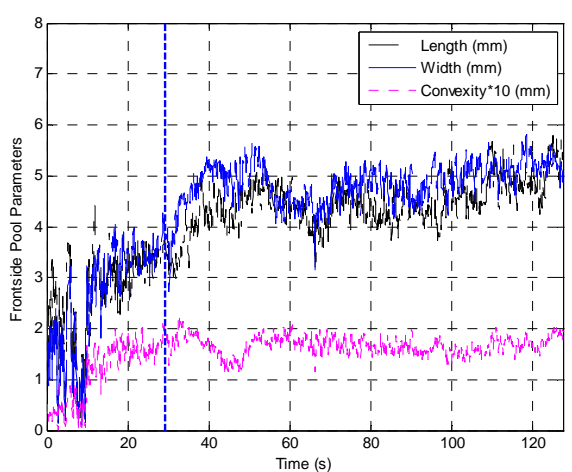

(b)

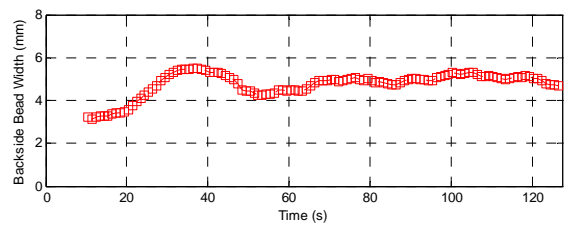

(d)

Fig.16 Closed-loop control experiment results under step change of the traveling speed : (a) control input (b) measured front-side weld pool characteristic parameters (c) backside appearance (d) measured backside bead width [112].

\section{Future research}

Learning human welder's behavior can help develop next generation intelligent welding machines and train welders faster. In this tutorial paper, various aspects of mechanizing the welder's intelligence are surveyed, including sensing of the weld pool, modeling of the welder's adjustments and this model-based control approach. A foundation is thus established to explore the mechanism and transformation of human welder's intelligence into robotic welding system.

Future work in the human welder intelligence modeling and control lies in the following areas. First, detailed human welder reaction other than welding current adjustments should be further modeled (including welding speed adjustments, welding torch orientations, etc.) Second, the model of the skilled human welder should be constructed and compared to the novice welder. This helps to understand the behavior of the skilled welder and helps to train welders faster. Third, advanced intelligent welding robots capable of adaptively control the welding process can be further designed.

\section{References}

[1] G. D. Uttrachi, 2007.Welder shortage requires new thinking. Welding Journal 86(1):6.

[2] Welding shortage fact sheet, American Welding Society, 2007, http://files.aws.org/pr/shortagefactsheet.pdf

[3] R. O' Brien, Ed., Welding Handbook, 8th Edition 2 - Welding Processes.AWS, 1998.

[4] W.J. Zhang, Y.M. Zhang, 2012, "Modeling of human welder response to 3D weld pool surface: Part I 
- principles," Welding Journal, 91: 310s-318s.

[5] W.J. Zhang, Y.M. Zhang, 2012, "Modeling of human welder response to 3D weld pool surface: Part II - results and analysis," Welding Journal, 91: 329s-337s.

[6] D. J. Kotecki, D. Cheever, and D. Howden, 1972 "Mechanism of ripple formation during weld solidification," Welding Journal, 51(8): 386s- 391s.

[7] R. Renwick and R. Richardson, 1983, "Experimental investigation of GTA weld pool oscillations," Welding Journal, 62(2): 29s-35s.

[8] M. Zacksenhouse and D. Hardt, 1984, "Weld pool impedance identification for size measurement and control," ASME Journal of Dynamic Systems, Measurement, and Control, 105(3): 179-184.

[9] Y.H. Xiao and G. den Ouden, 1993, "Weld pool oscillation during GTA welding of mild steel," Welding Journal, 72(8): 428s-434s.

[10] A.J.R. Anedenroomer and G. den Ouden, 1998, "Weld pool oscillation as a tool for penetration sensing during pulsed GTA welding," Welding Journal, 77(5):181-187.

[11] K. Andersen, G.E. Cook and R.J. Barnett, 1997, "Synchronous weld pool oscillation for monitoring and control," IEEE Transactions on Industry Applications, 33(2): 464-471.

[12] J. Ju, Y. Suga and K. Ogawa, 2004, "Penetration control by monitoring molten pool oscillation in TIG arc welding," International Journal of Offshore and Polar Engineering, 14(2): 145-149.

[13] B. Yudodibroto, M. Hermans, Y. Hirata, and G. den Ouden G, 2004, "Influence of filler wire addition on weld pool oscillation during gas tungsten arc welding," Science and Technology of Welding and Joining, 9(2): 163-168.

[14] J.D. Aussel, A.Le Brun and J.C. Baboux, 1998, "Generation acoustic wave by laser: Theoretical and experimental study of the emission source," Ultrasonics, 24: 246-255.

[15] A. V. Clark, S. R. Schaps and C.M. Fortunko, 1992, "Well-shielded EMAT for on-line ultrasonic monitoring of GMA welding," in Proceedings of Institute of Electrical and Electronics Engineers Ultrasonic Symposium, Orlando, FL.

[16] G. Graham and I. Ume, 1997, "Automated system for laser ultrasonic sensing of weld penetration," Mechatronics, 7(8): 711-721.

[17] S. Hopko and I. Ume, 1999, "Laser generated ultrasound by material ablation using fiber optic delivery," Ultrasonics, 37(1): 1-7.

[18] E. Siores, 1988, "Development of a real time ultrasonic sensing system for automated and robotic welding," Ph.D. dissertation, Brunel University.

[19] A. Kita, 2005, "Measurement of weld penetration depth using non-contract ultrasound method," Ph.D. dissertation, Georgia Institute of Technology.

[20] B. Mi and C. Ume., 2006, "Real time weld penetration depth monitoring with laser ultrasonic sensing system," Transactions of ASME: Journal of Manufacturing Science and Engineering, 128: 280-286.

[21] W. Chen and B. Chin, 1990, "Monitoring joint penetration using infrared sensing techniques," Welding Journal, 69(4): 181s-185s.

[22] B.A. Chin, N.H. Madsen, and J.S. Goodling, 1983, "Infrared thermography for sensing the arc welding process," Welding Journal: 227-234.

[23] P. Banerjee et al., 1995, "Infrared sensing for on-line weld shape monitoring and control," ASME Journal of Engineering for Industry, 117: 323-330.

[24] H. C. Wikle, R. H. Zee, and B. Chin, 1999, "Sensing system for weld process control," Journal of Materials Processing Technology, 89-90: 254-259.

[25] J. Song and D. Hardt, 1993, "Closed-loop control of weld pool depth using a thermally based depth 
estimator," Welding Journal, 72(10): 471s-478s.

[26] J. Song and D. Hardt, 1994, "Dynamic modeling and adaptive control of the gas metal arc welding process," ASME Journal of Dynamic Systems, Measurement, and Control, 116(3): 405-413.

[27] S. Nagarajan, P. Banerjee, W. Chen and B. A. Chin, 1992, "Control of the welding process using infrared sensors," IEEE Transactions on Robotics and Automation, 8(1): 86-93.

[28] C. Balfour, J. Smith, and A. Al-Shamma, 2006, “A novel edge feature correlation algorithm for realtime computer vision-based molten weld pool measurements," Welding Journal, 85(1): 1s-8s.

[29] C. Fan, F. Lv, and S. Chen, 2009, "Visual sensing and penetration control in aluminum alloy pulsed GTA welding," International Journal of Advanced Manufacturing Technology, 42(1):126-137.

[30] H. Ma, S. Wei, T. Lin, etc., 2010, "Binocular vision system for both weld pool and root gap in robot welding process," Sensor Review, 30(2):116-123.

[31] M. Lin and T. Eagar, 1985, "Influence of arc pressure on weld pool geometry," Welding Journal, 64(6):163-169.

[32] S.I. Rokhlin and A.C. Guu, 1993, “A study of arc force, pool depression, and weld penetration during gas tungsten arc welding," Welding Journal, 72(8):381-390.

[33] W. Zhang, Y. Liu, and Y. M. Zhang, 2012, "Characterization of three-dimensional weld pool surface in gtaw," Welding Journal, 91(7):195s-203s.

[34] Y. Tang, X. Su, F. Wu, and Y. Liu, 2009, “A novel phase measuring deflectometry for aspheric mirror test," Optic Express, 17(22):19778-19784.

[35] W. Zhao, X. Su, Y. Liu, and Q. Zhang, 2009, “Testing an aspheric mirror based on phase measuring deflectometry," Optic Engineering, 48(10): 103603.

[36] L. Huang, C. S. Ng, and A. K. Asundi, 2011, "Dynamic three-dimensional sensing for specular surface with monoscopic fringe reflectometry," Optics Express, 19(13): 12809-12814.

[37] S. Zhang and P. S. Huang, 2006, "High-resolution, real-time three-dimensional shape measurement," Optic Engineering, 45(12):123601.

[38] S. Zhang, 2010, "Recent progresses on real-time 3d shape measurement using digital fringe projection techniques," Optic Lasers Engineering, 48(2):149-158.

[39] J. Balzer and S. Werling, 2010, "Principles of shape from specular reflection," Measurement, 43(10):1305-1317.

[40] G. J. Zhang, Z. H. Yan, and L. Lin, 2006, "Reconstructing a three- dimensional p-gmawweld pool shape from a two-dimensional visual image," Measurement Science andTechnology, 17(7):1877-1882.

[41] Z. H. Yan, G. J. Zhang, and L. Wu, 2011, "Simulation and controlling for weld shape process in pgmaw based on fuzzy logic," Proceedings of the 2011 IEEE International Conference on Mechatronics and Automation:2078-2082.

[42] C. Mnich, F. Al-Bayat, C. Debrunner, and et al., 2004, "In situ weld pool measurementusing stereovision," Proceedings of 2004 Japan-USA Symposium on FlexibleAutomation, ASME:1-2.

[43] J. Steele, C. Mnich, C. Debrunner, T. Vincent, and S. Liu, 2005, “Development of closed-loop control of robotic welding processes," Industrial Robot: An International Journal, 32(4):35-55.

[44] D. Y. Choong and J. Lee., 2004, "3-d measurement of weld pool using biprism stereovision sensor," Http://joining1.kaist.ac.kr/research/vision.htm, Seoul National University.

[45] C. X. Zhao, I. M. Richardson, S. Kenjeres, C. R. Kleijn, and Z. Saldi, 2009, “A stereo vision method for tracking particle on the weld pool surface," Journal of Applied Physics, 105(12): 104-123.

[46] Q. Y. Du, S. B. Chen, and T. Lin, 2006, "Reconstruction of weld pool surface based onshape from shading," Journal of Mechanical Engineering, 19(2):168-171. 
[47] J. F. Wang, W. Y. Wang, and S. B. Chen, 2007, "Extraction of welding pool shape usinglinear approximation."Transactions of the China Welding Institution, 28(8):54-56.

[48] J. Wang, W. Wang, and S. Chen, 2009, "Inspection of welding pool height from shading in pulsed gtaw with wire filler," Industrial Robot: An International Journal, 36 (3):270-276.

[49] D. Zhao, J. Q. Yi, S. Chen, L. Wu, and Q. Chen, 2003, "Extraction of three-dimensionalparameters for weld pool surface in pulsed GTAW with wire filler," Journal of Manufacturing Science and Engineering, 125:493-503.

[50] L. P. Li, X. Q. Yang, F. Y. Zhang, and T. Lin, 2011, "Research on surface recoverof aluminum alloy p-GTAW pool based on SFS," Robotic Welding, Intelligence andAutomation, Lecture Notes in Electrical Engineering, 88:307-314.

[51] R. Kovacevic and Y. M. Zhang, 1996, "Sensing free surface of arc weld pool using specular reflection: principle and analysis," Proceedings of the Institution of Mechanical Engineers, Part B, Journal of Engineering Manufacturing, 210(6):553-564.

[52] G. Saeed and Y. M. Zhang, 2003, "Mathematical formulation and simulation of specular reaction based measurement system for gas tungsten arc weld pool surface," Measurement Science and Technology, 14(8):1671-1682.

[53] X. P. Ai, N. S. Liu, Y. Q. Wei, X. Hu, and X. R. L. S. Wei, 2009, "Study on image acquisition in 3-d sensor system of arc welding pool surface shape using grating projection," Proceedings of SPIE, 75067528.

[54] Y. Q. Wei, N. S. Liu, X. Hu, and X. Ai, 2011, "Phase-correction algorithm of deformed grating images in the depth measurement of weld pool surface in gas tungsten arc welding," Optical Engineering, 50:5.

[55] G. Saeed, M. J. Lou, and Y. M. Zhang, 2004, “Computation of 3d weld pool surface from the slope field and point tracking of laser beams," Measurement Science and Technology, 15(2):389-403.

[56] H. S. Song and Y. M. Zhang, 2007, "Image processing for measurement of three-dimension al gta weld pool surface," Welding Journal, 86(10):323s-330s.

[57] X. J. Ma and Y. M. Zhang., 2011, "Gas metal arc weld pool surface imaging: Modeling and processing," Welding Journal, 90(5):85s-94s.

[58] D.T. McRuer, E.S. Krendel, 1957, "Dynamic response of human operators," WADC-TR-56-524. US Airforce.

[59] D.T. McRuer, H. R. Jex, 1967, "A review of quasi-linear pilot models," IEEE Transaction on Human Factor Electronics, 8: 231-249.

[60] D. McRuer, D. Graham, E. Krendel, W. Reisener, 1965. "Human Pilot Dynamics in Compensatory Systems.Technical report,"AFFDL-TR-65-15, Air Force Flight Dynamics Laboratory, WrightPatterson AFB. Ohio.

[61] D. L. Kleiman, S. Baron, andW. H. Levison, 1970,"An optimal model of human response, part I. Theory and validation," Automatica, 6: 357-369.

[62] D. L. Kleiman, S. Baron, andW. H. Levison, 1970. "An optimal model of human response, part II.Prediction of human performance in a complex task," Automatica, 6: 371-383.

[63] M. Tomizuka, and D. E. Whitney, 1975, "Optimal discrete finite preview problems (why and how is future information important?)," Journal of Dynamics and System Measurement Control 97:319-325.

[64] M. Tomizuka, and D. E. Whitney, 1976, "The human operator in manual preview tracking (an experiment and its modeling via optimal control),"Journal of Dynamics and System Measurement Control 98: 407-413.

[65] L. R. Yong, 1969, "On adaptive manual control," IEEE Transaction on Man and Machine System 10: 
292-331.

[66] W. S. Kim, F. Tendick, S. R. Ellis, andL. W.Stark, 1987, "A comparison of position and rate control of tele-manipulation with consideration of manipulator system dynamics," IEEE Journal of Robot Automation 3: 426-436.

[67] H. Inooka, T. Koitabashi, 1990, "Experimental studies of manual optimization in control tasks," IEEE Control System Magazine, 10: 20-23.

[68] C. R.Kelly, 1968, Manual and automatic control, A theory of manual control and its application to manual and automatic systems. New York: Wiley.

[69] R. B. Erwin, V. K. Robert, 1998, "Estimation of time-varying delay time in non-stationary linear systems: an approach to monitor human operator adaption in manual tracking tasks,"IEEE transactions on system, man and cybernetics-part A: system and humans, 28(1): 89-99.

[70] M. Arif, H. Inooka, 1999, "Iterative manual control model of human operator,"Biological Cybernetics, 81: 445-455.

[71] J. B. Davidson, and D. K. Schmit, 1992, "Modified optimal control pilot model for computer-aid design and analysis," Technical Report TM-4384, NASA.

[72] D. B. Doman, and M. R.Anderson, 2000, "A fixed-order optimal control model of human operator response," Automatica, 36: 409-418.

[73] Y. Uno, M. Kawato and R. Suzuki, 1989, "Formation and control of optimal trajectory in human multijoint arm movement-minimum torque change model,"Biological Cybernetics, 61: 89-101.

[74] M. Ito, 2000, "Internal model visualized,"Nature, 403: 153-154.

[75] H. Imamizu, S. Miyauchi, T. Tamada, etc., 2000, "Human cerebellar activity reflection an acquired internal model of a new tool,"Nature, 403: 192-195.

[76] R. C. Miall, D. J. Weir, D. M. Wolpert, and J. F. Stein, 1993, "Is the cerebellum a Simith predictor," Journal of Motor Behavior , 25(3): 203-216.

[77] L. K.Chen, A. G. Ulsoy, 2000. "Identification of a nonlinear driver model via narmax modeling," Proceedings of American Control Conference.2533-2537.

[78] T. Tsuji, Y. Tanaka,.2005. "Tracking control properties of human-robotic systems based on impedance control," IEEE Transactions on Systems, Man, and Cybernetics- Part A: Systems and Humans.35(4): 523-535.

[79] E. Itoh, and S.Suzuki,2005. "Nonlinear approach for human internal models: Feedforward and feedback roles in pilot maneuver,"Systems. Man and Cybernetics. 2005 IEEE International Conference.3: 2455 $-2462$.

[80] I. I. Delice, and S. Ertugrul, 2007. "Intelligent modeling of human driver: A survey,"2007 IEEE Intelligent Vehicles Symposium. 648 - 651.

[81] S. Ertugrul, 2008. "Predictive modeling of human operators using parametric and neuro-fuzzy models by means of computer-based identification experiment," Engineering Applications of Artificial Intelligence. 21: 259-268.

[82] R. W.Brockett, 1999, "Minimum attention control," in Proceeding of 36th IEEE CDC San Diego, $\mathrm{CA}: 2628-2632$.

[83] K. J. Astrom, B. M.Bernhardsson,2002, "Comparison of Riemann and lebesgue sampling for first order stochastic systems," in Proceeding of 41st IEEE CDC Las Vegas, NV:2011-2016.

[84] R. Antunes, F. V. Coito, and H. Duarte-Ramos, 2011, "A linear approach towards modeling human behavior," DoCEIS, IFIP AICT 349: 305-314.

[85] O. Ceik, S. Ertugrul, 2007, "Predictive human operator model to be utilized as controller using linear, 
neuro-fuzzy and fuzzy-ARX modeling techniques," Engineering Applications of Artificial Intelligence, 23:595-603.

[86] N.Yamada, S.Inagaki, T.Suzuki, etc., 2006, "Behavior modeling in man-machine cooperative system based on stochastic switched dynamics,"Proceeding of 2006 IEEE international Conference on Robotics and Automation:3618-3623.

[87] H. Okuda, S. Hayakawa, T. Suzuki, N. Tsuchida, 2011, "Parameter design of switched assist controller for man-machine cooperative system with human behavior model based on hybrid system,"Electrical Engineering in Japan, 177(1): 55-63.

[88] K. Tervo, 2010, "Discrete data-based state feedback model of human operator,"2010 IEEE/ASME International Conference on Mechatronics and Embedded Systems and Applications (MESA): 202- 207.

[89] K. Tervo and A. Mannien, 2010, "Analysis of model orders in human dynamics identification using linear polynomial and Hammerstein-wiener structures,"2010 IEEE International Conference on Networking, Sensing and Control: 614- 620.

[90] L. A. Zadeh, 1965, "Fuzzy sets," Information and Control, 8:338-353.

[91] J.S.R. Jang, E. Mizutani, and C.-T. Sun, 1997, Neuro-Fuzzy and Soft Computing, A Computational Approach to Learning and Machine Intelligence, Prentice Hall, Upper Saddle River, NJ.

[92] A. Kandel, 1992, Fuzzy expert systems, CRC Press, Inc., Boca Raton, FL.

[93] M. Sugeno and G. T. Kang, 1988, "Structure identification of fuzzy model," Fuzzy Sets and Systems, 28:15-33.

[94] T. Takagi and M. Sugeno, 1985, "Fuzzy identification of systems and its applications to modeling and control," IEEE Transactions on Systems, Man and Cybernetics, 15:116-132.

[95] B. Kosko, 1991, Neural networks and fuzzy systems: a dynamical systems approach, Prentice Hall, Upper Saddle River, NJ.

[96] C.-C. Lee, 1990, "Fuzzy logic in control systems: fuzzy logic controller-part 1," IEEE Transactions on Systems, Man and Cybernetics, 20(2):404-418.

[97] C.-C. Lee, 1990, "Fuzzy logic in control systems: fuzzy logic controller-part 2," IEEE Transactions on Systems, Man and Cybernetics, 20(2):419-435.

[98] E.H. Mamdani and S. Assilian,1975, "An experiment in linguistic synthesis with a fuzzy logic controller," International Journal of Man-Machine Studies, 7(1):1-13.

[99] Y. Tsukamoto, 1979, An approach to fuzzy reasoning method. In Madan M. Gupta, Rammohan K. Ragade, and Ronald R. Yager, editors, Advances in fuzzy set theory and applications:137-149, NorthHolland, Amsterdam.

[100] A.E. Bryson and Y.-C. Ho, 1969, Applied optimal control, Blaisdell, New York.

[101] D.E. Rumelhart, G.E. Hinton, and R.J. Williams, 1986, "Learning internal representations by error propagation," Parallel distributed processing: explorations in the microstructure of cognition, 1:318362, MIT Press, Cambridge, MA.

[102] E.H. Mamdani, and S.Assilian,1975, "An experiment in linguistic synthesis with a fuzzy logic controller,” International Journal of Mechanical Studies, 7(1): 1-13.

[103] K. Hayashi, et.al., 1995, "Neuro fuzzy transmission control for automobile with variable loads," IEEE Transactions on Control Systems Technology, 3(1): 49-53.

[104] K. Tanaka, M.Sano, and H. Watanabe, 1995, "Modeling and Control of Carbon Monoxide Concentration Using a Neuro-Fuzzy Technique," IEEE Transactions on Fuzzy Systems, 3(3): 271-279.

[105] R. Kovacevic, and Y.M. Zhang, 1997, "Neurofuzzy model-based weld fusion state estimation,” IEEE Control System Magazine, 17(2): 30-42. 
[106] Y.M. Zhang, and R.Kovacevic, 1998, "Neurofuzzy model based control of weld fusion zone geometry," IEEE Transactions on Fuzzy Systems, 6(3): 389-401.

[107] J.S.R. Jang, and C.T. Sun, 1995, “Neuro-Fuzzy Modeling and Control”, Proceedings of the IEEE, 83(3): 378-406.

[108] J.S.R. Jang, 1993, “ANFIS: Adaptive-network-based Fuzzy Inference Systems”, IEEE Transactions on Systems, Man, and Cybernetics, 23(3): 665-685.

[109] W. Lih, et.al., 2008, “Adaptive Neuro-Fuzzy Inference System Modeling of MRR and WIWNU in CMP Process with Sparse Experimental Data,” IEEE Transactions on Automation Science and Engineering, 5(1): 71-83.

[110] J. Zhai, et.al., 2009, “ The Dynamic Behavioral Model of RF Power Amplifiers with the Modified ANFIS,"IEEE Transactions on Microwave Theory and Techniques, 57(1): 27-35.

[111] M. Imen, M. Mansouri, and M.A.Shoorehdeli, 2011, “Tracking Control of Mobile Robot Using ANFIS," Proceedings of the 2011 IEEE International Conference on Mechatronics and Automation, Beijing, China.

[112] Y.K. Liu, W.J. Zhang, Y.M. Zhang, 2013, "Neuro-fuzzy Based Human Intelligence Modeling and Robust Control in Gas Tungsten Arc Welding Process," Proceedings of the 2013 American Control Conference (2013 ACC), Washington DC, USA. 